Int. J. Dev. Biol. 53: 433-442 (2009)

doi: $10.1387 / \mathrm{ijdb} .082643 \mathrm{pm}$

\title{
Mammalian hibernation: differential gene expression and novel application of epigenetic controls
}

\author{
PIER MORIN Jr. ${ }^{1}$ and KENNETH B. STOREY*,2 \\ ${ }^{1}$ Friedrich Miescher Institute for Biomedical Research, Maulbeerstrasse, Basel, Switzerland and \\ ${ }^{2}$ Institute of Biochemistry and Department of Chemistry, Carleton University, Ottawa, Ontario, Canada
}

\begin{abstract}
This review highlights current information about the regulatory mechanisms that govern gene expression during mammalian hibernation, in particular the potential role of epigenetic controls in coordinating the global suppression of transcription. Hibernation is characterized by long periods of deep torpor (when core body temperature drops to near ambient) that are interspersed with brief arousal periods back to euthermia. Entry into torpor requires coordinated controls which strongly suppress and reprioritize all metabolic functions, including global controls on both transcription and translation. At the same time, however, selected hibernation-specific genes are up-regulated under the control of specific transcription factors to support the torpid state; this includes genes that encode proteins involved in lipid fuel catabolism and in long term cytoprotection (e.g. antioxidants, chaperones). We evaluate the currently available information on global transcriptional suppression in hibernation and propose that epigenetic mechanisms such as DNA methylation, histone modification, SUMOylation and the actions of sirtuins play crucial roles in transcriptional suppression during torpor. Global controls providing translational suppression also occur during hibernation including reversible phosphorylation control of ribosomal initiation and elongation factors as well as polysome dissociation. We also present initial data that mRNA transcripts are regulated via inhibitory interactions with microRNA species during torpor and provide the first evidence of differential expression of miRNAs in hibernators. When taken together, these mechanisms provide hibernators with multiple layers of regulatory controls that achieve both global repression of gene expression and selected enhancement of genes/proteins that achieve the hibernation phenotype.
\end{abstract}

KEY WORDS: hypometabolism, histone modification, epigenetics, microRNA

\section{Introduction}

The control of gene expression is crucial for any living organism. The genome encodes all of the possibilities for the life of each organism but it is the layers of regulatory controls on gene expression that define how that life develops, grows, responds to its environment, deals with disease and pathogens, and ultimately ages and dies. Control of gene expression is regulated in many different ways including basic regulation of the transcriptional machinery, the actions of transcription factors and cofactors in regulating the expression of specific suites of genes in response to many different intra- and extracellular signals, chromatin accessibility (e.g. euchromatin versus heterochromatin), and multiple epigenetic modifications of genes and their associated chromatin proteins (e.g. histones). Controls also extend beyond the nucleus to regulate both the mRNA transcripts themselves (e.g. by splicing, transcript longevity, and multiple inhibitory mechanisms) and the ribosome translation machinery so that ultimately very precise regulation is achieved over the final protein products that implement the changes initiated by altered gene expression.

For us, one of the most fascinating uses of control over gene

Abbreviations used in this paper: ATF, activating transcription factor; BAT, brown adipose tissue; CREB, cAMP response element-binding protein; FABP, fatty acid binding protein; FOXO, forkhead class $\mathrm{O}$ transcription factor; HDAC, histone deacetylase; HIF, hypoxia inducible factor; miRNA, microRNA; PPAR, peroxisome proliferator-activated receptor; RT-PCR, real time polymerase chain reaction; Sir, sirtuin; SUMO, small ubiquitin-related modifier; $\mathrm{Tb}$, body temperature; WAT, white adipose tissue.

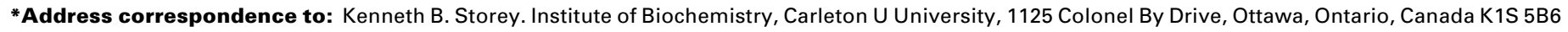
Fax: +1-613-520-3749. e-mail: kenneth_storey@carleton.ca - web: www.carleton.ca/ kbstorey
}

Published online: 24 April 2009.

ISSN: Online 1696-3547, Print 0214-6282

(c) 2009 UBC Press

Printed in Spain 
expression is the regulation of transitions by organisms between states of normal activity and states of torpor or dormancy. Although not part of human physiology, hypometabolism is a key survival strategy for enormous numbers of organisms allowing life extension in the face of a variety of environmental stresses (e.g. low temperature, oxygen lack, nutrient limitation, dehydration, among others) (Storey and Storey, 2004, 2007). The focus of the present article is mammalian hibernation, a seasonal state characterized by prolonged periods of deep torpor where metabolic rate can plunge to less than $5 \%$ of the normal resting rate. Hibernation is the most extreme example of hypometabolism among mammalian species and the lessons learned from studies of the regulation of hibernation have multiple potential applications to human biology and medicine, addressing concerns such as ischemia resistance, hypothermic organ preservation, prevention of muscle atrophy, and even the development of inducible torpor as an aid to long term space flight (Storey, 2004; Lee and Hallenbeck, 2006; Shavlakadze and Grounds, 2006). Another form of mammalian hypometabolism is daily torpor, a common phenomenon that is characterized by a much shallower reduction of core body temperature (Tb) and a much shorter time frame (hours instead of days) (Geiser, 2004). In the present article, our discussion focuses almost exclusively on the deep torpor of hibernation although we draw a few examples from studies of daily torpor. We summarize the recent advances in understanding the control of gene expression in hibernation with a particular emphasis on global mechanisms of transcriptional and translational suppression including two new avenues of research: epigenetic regulation of gene transcription and the role of microRNA (miRNA) in inhibiting the translation of messenger RNA (mRNA).

\section{Life in the cold: the basics of hibernation}

Mammalian hibernation is fascinating. Animals sink into a deep torpor and abandon one of the basic tenets of mammalian life homeothermy. Metabolic rate is strongly suppressed, often to as little as $1-5 \%$ of the euthermic resting rate at high $\mathrm{Tb}\left(\sim 37^{\circ} \mathrm{C}\right)$ (Geiser, 2004) and, as a result, core body temperature falls to near ambient (often as low as $0-5^{\circ} \mathrm{C}$ ) and all physiological functions are greatly slowed. For example, heart rate in ground squirrels can drop from a normal rate of 200300 to just 3-5 beats per minute. Overall, by hibernating, animals can conserve about $90 \%$ of the energy that it would otherwise take to remain euthermic over the winter months (Wang and Lee, 1996).

To prepare for hibernation, animals undergo a period of hyperphagia during the late summer, laying down huge reserves of lipids in white adipose tissue (WAT) that often increases

Fig. 1. Body temperature over the course of a year from June to May in the golden-mantled ground squirrel, Spermophilus lateralis. The inset shows the pattern of three torpor-arousal cycles highlighting multiple stages: the entrance into torpor (EN) which lasts up to 12 hours, early torpor (ET) within 48 hours of entering torpor, late torpor ( $L T)$, arousal (AR) with a duration of $\sim 2$ hours, and finally interbout arousal (IBA) with a duration of 20 hours. Taken from Carey et al. (2003). body mass by about 50\% (Wang and Lee, 1996). Diet selection also leads to an elevated proportion of polyunsaturated fatty acids in lipid depots that allows these to remain fluid, and able to be metabolized, when $\mathrm{Tb}$ sinks to near $0^{\circ} \mathrm{C}$ during torpor (Frank and Storey, 1995). The hibernation season may last for 6-7 months and consists of prolonged bouts of deep torpor (several days to weeks) that are interspersed with short periods of arousal when animals rewarm themselves back to euthermia for several hours (Figure 1). Typically, there is a progressive increase in the length of torpor bouts during the autumn with maximum lengths in midwinter followed by shortening again in the spring. The maximum length of torpor episodes also varies between species and as a function of ambient temperature during hibernation (Buck and Barnes, 2000). Arousal from torpor is initially and primarily fueled by non-shivering thermogenesis in brown adipose tissue (BAT) but after $\mathrm{Tb}$ rises above about $15^{\circ} \mathrm{C}$ skeletal muscle shivering also contributes to rewarming. Multiple reasons for these periodic arousals have been postulated such as a need to eliminate metabolic wastes, readjust neural circuits, or recharge the immune system but no single regulatory factor has yet been identified (Prendergast et al., 2002; Heller and Ruby, 2004).

Our interest in hibernation is at the molecular level and our research has two main themes: (1) the global regulatory mechanisms that coordinate and control reversible excursions into deep torpor, and (2) the specific adaptations and selective gene expression that are needed to support cold torpor in a mammal (Storey, 2003, 2004).

\section{Metabolic suppression in hibernation}

Entry into torpor is a highly regulated process that involves both a profound suppression of the rates of all cellular processes (with a particular emphasis on balancing ATP-producing and ATP-consuming functions) and a reprioritization of cellular activities (e.g. energy expenditure to maintain transmembrane ion

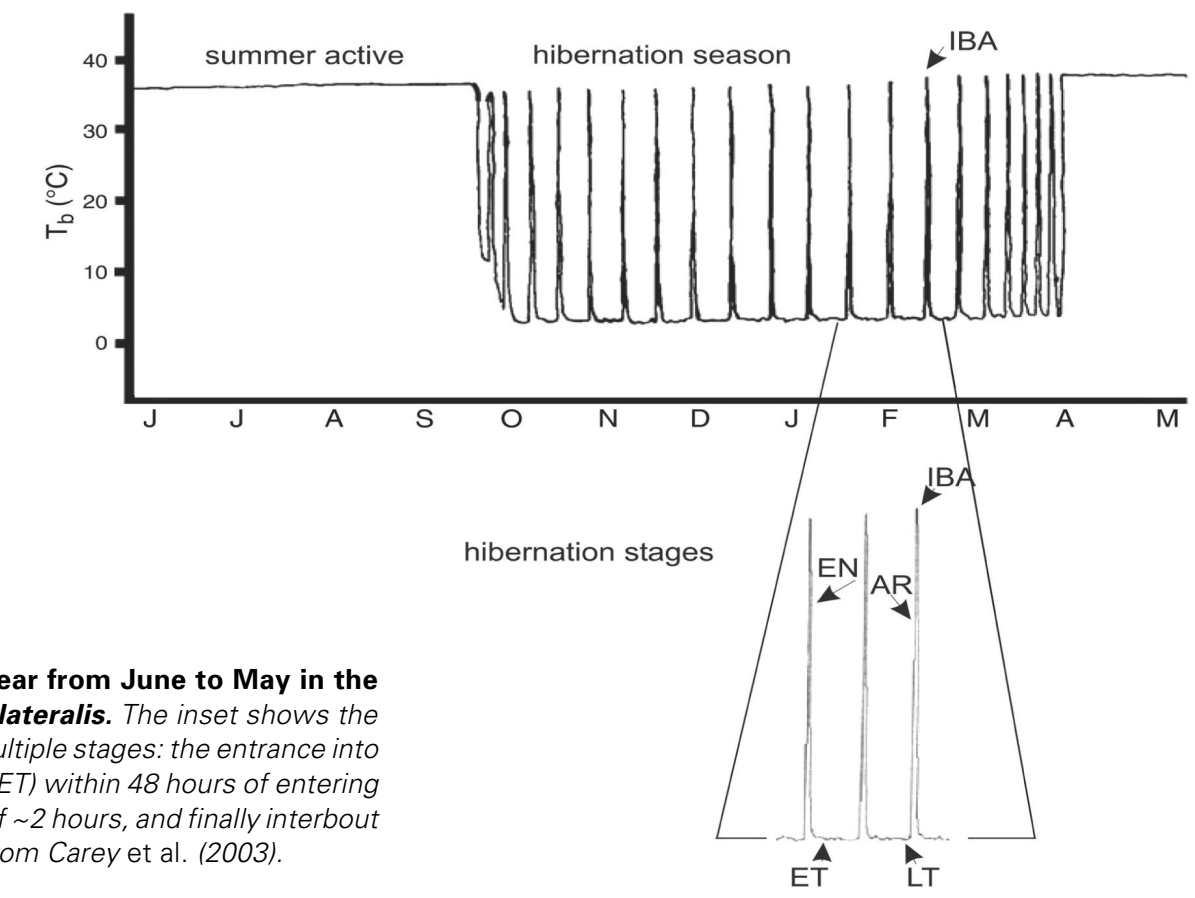


gradients takes precedence over biosynthesis which is very strongly suppressed). Some of the major ATP-consuming processes in cells include transmembrane ion transport, gene transcription, and protein translation and, not surprisingly, the rates of all of these processes as well as of fuel catabolism and many other metabolic functions are strongly suppressed when hibernators enter torpor (Frerichs et al., 1998; MacDonald and Storey, 1999; van Breukelen and Martin, 2002; Storey and Storey, 2004, 2007). For example, plasma membrane $\mathrm{Na}^{+} \mathrm{K}^{+}$-ATPase activity was reduced by $60 \%$ during hibernation (MacDonald and Storey, 1999) and the activity of sarco(endo)plasmic reticulum $\mathrm{Ca}^{2+}$ ATPase as well as the levels of other proteins associated with calcium signaling were similarly reduced (Malysheva et al., 2001). Strong overall suppression of ATP-expensive protein synthesis has also been confirmed in hibernators in both in vivo and in vitro studies that monitored ${ }^{14} \mathrm{C}$-leucine or ${ }^{3} \mathrm{H}$-leucine incorporation into proteins (Frerichs et al., 1998; Hittel and Storey, 2002; Osborne et al., 2004). Finally, the overall rates of gene transcription are also greatly reduced during deep torpor bouts in hibernators. For example, the rate of $\left[{ }^{3} \mathrm{H}\right]$-uridine incorporation into RNA was reduced by 8-fold in brain of torpid ground squirrels compared with euthermic animals (Bocharova et al., 1992). A similar result was seen when $\left[{ }^{3} \mathrm{H}\right]$-uridine incorporation into RNA was measured in multiple organs of hibernating Syrian hamsters (Mesocricetus auratus) (Osborne et al., 2004) and was also indicated from nuclear run-on assays performed on liver extracts of golden-mantled ground squirrels (van Breukelen and Martin, 2002). A reduction in energetically-costly transcription was also seen in Djungarian hamsters (Phodopus sungorus) undergoing daily torpor bouts (Berriel Diaz et al., 2004).

The central mechanism involved in the suppression of many metabolic functions during torpor has proven to be reversible protein phosphorylation, mediated by protein kinases and protein phosphatases. Indeed, reversible phosphorylation is a fundamental control mechanism of metabolic rate depression across phylogeny (Storey and Storey, 2004, 2007). For example, suppression of $\mathrm{Na}^{+} \mathrm{K}^{+}$-ATPase activity in hibernators is achieved by phosphorylation of the enzyme (MacDonald and Storey, 1999) as is a strong reduction in the activities of various enzymes of carbohydrate catabolism (Storey and Storey, 1990). For example, during hibernation in ground squirrels, the amount of pyruvate dehydrogenase present in the dephosphorylated active form fell from $60-80 \%$ in euthermia to less than $5 \%$ in hibernation (Brooks and Storey, 1992). Suppression of protein translation during torpor also comes from phosphorylation-mediated inactivation of selected ribosomal initiation and elongation factors (Frerichs et al., 1998, Chen et al., 2001).

\section{Transcriptional control in hibernation}

Although global rates of transcription are strongly suppressed during deep torpor, numerous studies have shown that a variety of genes (and their protein products) are specifically up-regulated when animals enter hibernation. Multiple forms of gene/protein screening have been particularly useful in this regard including cDNA library screening, DNA microarray screening, and protein screening via 2-dimensional electrophoresis (Andrews et al., 1998; Eddy and Storey, 2002; Eddy et al., 2005; Storey, 2003, 2004). Overall, screening studies have shown that only a small percentage of genes are up-regulated during hibernation whereas most show no change in transcript levels and some are specifically down-regulated. Interestingly, with regard to the latter group, genes/proteins related to transcription and translation appear to be particular targets for down-regulation. Thus, a recent study using a cDNA microarray approach to assess gene expression changes during daily torpor in Djungarian hamsters demonstrated that the functional group on the array that contained transcription-related genes was the most down-regulated of all groups in the comparison between torpid and euthermic states (Crawford et al., 2007). Furthermore, array screening of skeletal muscle from euthermic and hibernating thirteen-lined ground squirrels (Spermophilus tridecemlineatus) found that several components of the small and large ribosomal subunits were consistently down-regulated during torpor including L19, L21, L36a, S17, S12 and S29 (Eddy and Storey, 2002). RT-PCR confirmation carried out on three of these showed that S12, L36a and L21 transcript levels were reduced by $45-55 \%$ compared with euthermic controls.

Genes that are specifically up-regulated during hibernation are presumably key to the hibernation phenotype and are expressed to achieve specific survival needs during torpor. For example, fatty acid binding proteins (FABPs) are up-regulated to enhance the capacity for intracellular transport of fatty acids which are the primary fuels for metabolism during torpor (Hittel and Storey, 2002) whereas up-regulation of pyruvate dehydrogenase kinase results in the inhibition of pyruvate dehydrogenase and the subsequent suppression and sparing of carbohydrate fuels (Andrews et al., 1998). Selective gene up-regulation is under the control of transcription factors that bind to response elements present in the promoter region of genes to enhance transcriptional activity of the gene. Transcription factors typically regulate a suite of genes whose protein products are functionally related. Our research to date has identified several transcription factors that show increased protein expression or evidence of enhanced activity during torpor; depending on the transcription factor, evidence of activation can include increased dissociation from inhibitory subunits, elevated amounts of phosphorylated protein, increased translocation to the nucleus, or enhanced binding to DNA. Hence, just as in the case of reversible phosphorylation of metabolic proteins, this strategy gives animals the ability to upregulate very specific pathways or cell functions via controlling gene expression. Those that we have identified to date as hibernation responsive are primarily involved with fuel metabolism and with cytoprotection. For example, levels of the gamma isoform of the peroxisome proliferator-activated receptor (PPAR $\gamma$ ) were significantly elevated in both BAT and WAT of hibernating thirteen-lined ground squirrels (Eddy et al., 2004) and in all tissues examined (except brain) of hibernating little brown bats (Myotis lucifugus) (Eddy and Storey, 2003). PPAR $\gamma$ regulates the expression of a range of proteins/enzymes related to lipid metabolism such as FABPs (Way et al., 2001; Berger and Moller, 2002) and the action of PPAR $\gamma$ is therefore key to optimizing the organ-specific capacity to mobilize and/or catabolize lipid fuels during hibernation. The hypoxia inducible factor (HIF-1) also responds to hibernation. Protein levels of the oxygen-sensitive alpha subunit were significantly increased in BAT and skeletal muscle of ground squirrels during hibernation as compared with euthermic controls (Morin and Storey, 2005). HIF-1 is known to 
up-regulate the transcription of a variety of genes that enhance hypoxia tolerance including those that govern improved oxygen delivery to tissues (e.g. vascular endothelial growth factor, erythropoietin) and those that enhance the capacity of anaerobic glycolysis (Ratcliffe et al., 1998, Semenza, 2000, Hopfl et al., 2003). Up-regulation of selected genes under HIF-1 control may help hibernator organs deal with greatly reduced blood flow during torpor (ischemia) and/or apnoic breathing patterns that could cause hypoxia. Levels of the activating transcription factor (ATF4) also rose during hibernation in selected ground squirrel organs and, furthermore, the amount of ATF4 in the nucleus increased together with greatly enhanced nuclear levels of the ATF4 cofactor, the phosphorylated form of the cAMP response element-binding protein (CREB-1), strongly indicating increased transcription of genes under ATF4-pCREB-1 control (Mamady and Storey, 2008). One of the key actions of ATF4 is to enhance the expression of endoplasmic reticulum (ER) chaperone proteins and, indeed, both mRNA transcript and protein levels of the main ER chaperone, the glucose-regulated protein 78 , increased strongly in brain and brown adipose tissue of hibernating ground squirrels, two organs that also showed strong increases in ATF4 and p-CREB-1 levels (Mamady and Storey, 2006, 2008). Chaperones help to provide long term conformational stability to cellular proteins during prolonged cold torpor. Elevated levels of the Nrf2 transcription factor also occur during hibernation and correlate with increased expression of proteins involved in antioxidant defense such as $\mathrm{Cu} / \mathrm{Zn}$ superoxide dismutase, aflatoxin aldehyde reductase and heme oxygenase-1 (Morin et al., 2008a). Well-developed antioxidant defenses have two key roles in hibernation: (a) long term cytoprotection during prolonged torpor, and (b) defense against high rates of reactive oxygen species generation associated with the huge increase in oxygen consumption that powers thermogenesis during arousal. Strong increases in the levels of the phosphorylated active forms of several other transcription factors (CREB, ATF-2, Elk-1) also occurred during hibernation in skeletal muscle of bats, associated with an activation of the p38 MAPK (Eddy and Storey, 2007).

\section{Global control of transcription by epigenetic regula- tion: does it play a role in hibernation?}

In recent years, the new field of epigenetics has grown rapidly and produced major breakthroughs in understanding how global expression of a genome is regulated. It is now clear that epige- netic regulation plays a key role in development, various disease states (especially tumorigenesis) as well as senescence and aging (for review see Fraga and Esteller, 2007). Epigenetic modifications of DNA and chromatin are frequently heritable, providing a mechanism for changes in gene function without any change in the DNA nucleotide sequence. The best known epigenetic modifications are DNA methylation and post-transcriptional modification of histones by methylation, acetylation, ubiquitylation, or phosphorylation although histones are also subject to other modifications (e.g. sumoylation, citrullination, ADP-ribosylation).

Direct modification of DNA by methylation has a strong impact on gene expression. For example, hypermethylation of CpG islands located in the promoter region of a gene typically hinders the ability of the transcriptional machinery to transcribe that gene whereas a hypomethylated promoter facilitates the proper binding of the factors required for transcription (Tate and Bird, 1993). Methylation of $\mathrm{CpG}$ islands is also associated with the recruitment of histone modifying enzymes including histone deacetylases (HDACs) and histone methyltransferases (Sarraf and Stansheva, 2004). These enzymes catalyze histone modifications that modify the local chromatin environment resulting in enhanced or hindered transcription (Eden et al., 1998). This epigenetic mechanism has a significant role to play in many cancers. Studies have shown that the promoter region of key tumor suppressor genes are frequently hypermethylated in cancer cells and, therefore, unexpressed; these include the DNA repair gene BRCA1 in breast cancer, the cell cycle inhibitor $\mathrm{Rb}$ in retinoblastoma, and the pro-apoptotic DAPK in lymphoma (Dobrovic and Simpfendorfer, 1997; Ohtani-Fujita et al., 1997, Harden et al., 2003). Indeed, much research and drug discovery is currently focused on the use of DNA-demethylating agents which cause the re-expression of tumor suppressor genes. This approach to cancer treatment has been successful in cell lines and, more importantly, elicits antitumoral activity when administered to patients (Mack, 2006).

Posttranscriptional modifications of chromatin proteins, particularly histones, are also crucial mechanisms of epigenetic control. Acetylation of lysine residues on histones $\mathrm{H} 3$ and $\mathrm{H} 4$ results in an open DNA-protein structure whereas methylation of lysine residues produces the opposite result (Jenuwein and Allis, 2001). Acetylation neutralizes the positive charge on the histones, producing a conformational change that allows transcription factors and transcriptional regulatory complexes to have easier access to DNA promoter regions. On the other hand, the action of histone deacetylases replaces the positive charge on

Non Hibernation-Specific Genes Hibernation-Specific Genes

Euthermia
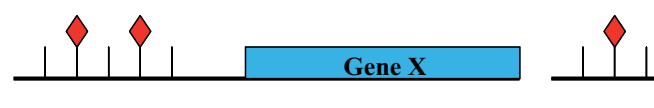

$\downarrow$

$\downarrow$

Torpor
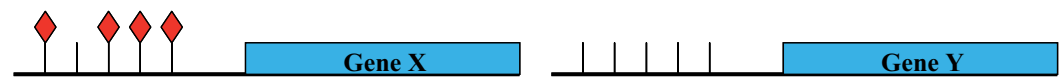

Fig. 2. A hypothesis on the importance of promoter methylation during hibernation. Genes that do not play a role in the hibernation response show enhanced methylation of their promoter regions as a means of turning off their transcription. However, the subgroup of hibernation-responsive genes show hypomethylation of their promoter regions during torpor which permits increased transcription. 
these proteins and leads to transcriptional silencing (Davie, 1998). Overall, an increase in DNA methylation combined with a decrease in histone acetylation usually correlates with reduced gene expression. Furthermore, there is emerging evidence that not just the overall trend of histone modifications, but the specific combinations of histone modifications is what regulates gene expression. Deciphering this "histone code" is not an easy task as multiple layers of transcriptional control participate in gene repression to different extents. This concept was reviewed recently by Lande-Diner and Cedar (2005) who highlight three layers of control that affect long term gene repression or silencing: (a) factors leading to gene repression, (b) DNA methylation, and (c) the timing at which DNA-replication occurs. By adding histone modifications to this list of layers, one can begin to grasp how complex epigenetic modifications can be.

In order to study this histone code, techniques have been developed that allow researchers to monitor DNA and histone modifications either on a global scale or focused on the promoter status of a selected gene. One particularly interesting approach relies on antibodies that recognize methylated DNA or a specific histone modification. For example, in order to assess DNA methylation status, DNA is first fragmented and the methylated segments are immunoprecipitated with antibodies against methylated DNA, an approach that is referred to as methyl-DIP. The immunoprecipitated DNA is then hybridized to a DNA microarray and compared with non-immunoprecipitated DNA, a method referred to as ChIP-on-chip. This provides global monitoring of the methylation status of different DNA regions. A comparable approach can evaluate histone status by using antibodies specific for a particular histone modification. For example, using this technique, a recent study identified variations in histone methylation that are specific to diabetes (Miao et al., 2007). Like any other technique that looks at genome-wide modifications, the risk of false positives is present with the ChIP-on-chip approach and so there is a need to validate these results. DNA methylation results should be further validated with methods such as bisulphite treatment combined with genomic sequencing. Briefly, bisulphite treatment changes unmethylated cytosine residues into uracil but leaves methylated cytosines unaltered. Following this treatment, sequencing is done using specific primers and the methylated cytosine residues in the original sequence can be inferred (Clark et al., 1994). These techniques have already been applied in various situations and, needless to say, they could easily be applied to examine transcriptional repression in hibernators.

There is no doubt that gene regulation in hibernating mammals must make clever use of the different layers of epigenetic control. It is reasonable to hypothesize that multiple epigenetic options could be applied in a reversible manner to repress global gene transcription when animals enter torpor and reactivate it again during arousal. Hibernation-specific genes would presumably be regulated oppositely; for example, hibernation-specific genes would predictably show an overall reduction in promoter methylation during torpor whereas the vast majority of genes should be oppositely regulated (Figure 2). This idea remains to be tested experimentally by analyzing global patterns of methylation and activities of DNA methyltransferases in euthermic versus hibernating states. One recent study touched on this regulatory mechanism as it applied to the control of one gene, HP-27, in chipmunks, Tamias asiaticus (Fujii et al., 2006). This gene is expressed in liver and produces a plasma protein that is present in euthermic animals but largely disappears from blood during hibernation. The authors reported that $\mathrm{CpG}$ islands located in the promoter region of HP-27 were hypomethylated in liver but hypermethylated in other organs, giving rise to the liver-specific expression pattern. One CpG dinucleotide (-161) within the binding site for the USF transcription factor that controls HP-27 was identified as particularly important to the regulation of HP-27 expression but the authors found no change in the methylation status of this residue between euthermic and hibernating states when assessed in either liver or kidney.

Several recent studies have shown that a variety of regulatory controls are involved in the global suppression of transcription in hibernation. Recent work in our lab examined three parameters of transcriptional control in skeletal muscle of thirteen-lined ground squirrels that could be used to provide reversible suppression of transcription during torpor (Table 1) (Morin and Storey, 2006). We found that the overall maximal activity of RNA polymerase II was reduced significantly during hibernation to just $58 \%$ of the activity in euthermic muscle despite a constant total amount of Pol II protein (as determined by immunoblotting). This argues for a stable, yet reversible, suppression of the activity state of the enzyme during torpor. The mechanism involved is not yet known but is likely a mode of covalent modification. Interestingly, the enzyme from muscle of hibernating squirrels showed an increased level of phosphorylation of Ser 5 in the peptide sequence (YSPTSPS) that is repeated multiple times in the $\mathrm{C}$ terminal domain. Although phosphorylation of Ser 5 (and Ser 2) on Pol II has been linked with transcriptional control, there is still considerable controversy about the significance of hyperphosphorylation in this domain (Kim et al., 1997).

TABLE 1

\section{EFFECT OF HIBERNATION ON INDICES OF TRANSCRIPTIONAL CONTROL IN SKELETAL MUSCLE OF THIRTEEN-LINED GROUND SQUIRRELS}

\begin{tabular}{ll}
\hline Histone deacetylase & \\
Activity & $1.82 \pm 0.20$ * \\
HDAC1 protein & $1.21 \pm 0.05^{*}$ \\
HDAC4 protein & $1.48 \pm 0.09$ * \\
Histone 3 & $0.99 \pm 0.16$ \\
$\quad$ Total H3 protein & $0.61 \pm 0.09$ * \\
Phospho-H3 (Ser 10) protein & $0.75 \pm 0.04$ * \\
Acetyl-H3 (Lys 23) protein & \\
RNA polymerase II & $0.57 \pm 0.04$ * \\
Activity & $1.05 \pm 0.19$ \\
Total Pol II protein & $1.79 \pm 0.21$ * \\
Phospho-Pol II (Ser 5) protein &
\end{tabular}

Ratio hibernating: euthermic.

Protein levels were measured by immunoblotting using antibodies that detected either total protein or the phosphorylation or acetylation of specific residues. For RNA polymerase II, the phospho-antibody detected phospho-Ser 5 in the heptapeptide repeat YSPTSPS in the Cterminal domain. Mean histone deacetylase activity in skeletal muscle was $31,878 \pm 2135$ and $57,972+7471$ relative fluorescence units per gram fresh weight in euthermic and hibernating animals, respectively. RNA polymerase II activity was measured in nuclear extracts of muscle as the rate of transcription of a gene for enhanced green fluorescent protein; activities were $0.63 \pm$ 0.03 and $0.36+0.01 \mathrm{ng}$ DNA produced $/ \mathrm{min} / \mu \mathrm{g}$ nuclear protein, respectively, for euthermic and hibernating conditions. Data are means $\pm S E M, n=3-4$ determinations on separate animals. Significance testing used the Student's t-test to compare hibernating and euthermic values $\left({ }^{*}\right.$ significantly different, $\mathrm{P}<0.05$ ); data were then expressed as ratios, hibernating:euthermic. Data are modified from Morin and Storey (2006). 
Our analysis also showed that global modifications of histones as well as changes in HDAC activities occurred during hibernation (Table 1). Total HDAC activity was $82 \%$ higher in skeletal muscle from hibernating versus euthermic ground squirrels, and this was supported by immunoblotting analysis that showed that the protein content of two isozymes, HDAC1 and HDAC4, increased significantly during hibernation. Not surprisingly, then, the level of acetylated histone H3 (Lysine 23) was 25\% lower in hibernator muscle, compared with euthermic controls. Levels of phosphorylated histone H3 (Serine 10) were also reduced by about $40 \%$ during hibernation. Both acetylation and phosphorylation of histones are associated with active transcription (Cheung et al., 2000) and, therefore, reduced amounts of phospho-H3 (Ser 10) and acetyl-H3 (Lys 23) protein suggest a reduction in transcriptional activity during hibernation that could control specific genes, suites of genes and/or provide global gene suppression. Although the literature available on histone and DNA modifications in hibernating animals remains sparse, the present results show that there is a definite need to investigate the status of these modifications in a broader way.

Nonetheless, the potential importance of some histone-modifying proteins in hibernators can be inferred from results reported for non-hibernating models. Such is the case for a class of proteins called the sirtuins. These proteins are HDACs that regulate chromatin silencing (Denu, 2003). In mammals, seven sirtuin homologs have been identified (Frye, 2000). Sirtuins initially seemed to have histones as their principal substrates as it was shown that SirT1 deacetylated specific residues of histones $\mathrm{H} 1, \mathrm{H} 3$ and $\mathrm{H} 4$ (Vaquero et al., 2004). However, more recent work has identified non-histone substrates for several sirtuin homologs. SirT1 also binds and deacetylates transcription factors such as NF-kappaB and forkhead class O (FOXO) transcription factors (Motta et al., 2004; Yeung et al., 2004). SirT1 deacetylation of FOXO3a leads to its translocation to the nucleus under oxidative stress (Brunet et al., 2004). Deacetylation of FOXO1 by SirT1 also affects its cellular localization and leads to expression of its target genes which in turn have an impact on gluconeogenesis and glucose release in hepatocytes (Frescas et al., 2005). SirT3 expression is also up-regulated in brown adipocytes following cold exposure and SirT3 can regulate thermogenesis in these cells (Shi et al., 2005). This study also showed that SirT3 triggered an increase in uncoupling protein 1 (the key protein in thermogenesis) and PGC-1 $\alpha$, a cofactor of the PPAR $\gamma$ transcription factor. Oppositely, the transcriptional activity of PPAR $\gamma$ was repressed by SirT1 (Picard et al., 2004). SirT1 can also deacetylate and activate PGC-1 $\alpha$ and has considerable impact in tissues such as liver, where it correlates with an increase in glucose release, and in muscle and BAT, where it positively affects thermogenesis (Rodgers et al., 2005; Lagouge et al., 2006). Overall, sirtuins seem to have an impact on histones and on a series of molecules involved in a variety of processes important to hibernators such as fat metabolism and thermogenesis. While these sirtuins have not yet been studied in hibernating mammals, it is reasonable to think that they play a pivotal role in the transcriptional control of key metabolic pathways in hibernators.

Another mechanism for the global control of transcription has recently been identified. This is the covalent attachment to proteins of the small ubiquitin-related modifier (SUMO). SUMOylation affects proteins involved in gene expression, chromatin structure, signal transduction, and maintenance of the genome (Hay, 2005). New work with thirteen-lined ground squirrels reported a huge increase in the SUMOylation of proteins in brain during hibernation with a concomitant drop in free SUMO levels; this was rapidly reversed during arousal (Lee and Hallenbeck, 2006; Lee et al., 2007). Liver and kidney also showed massive protein SUMOylation during hibernation. Given that transcription factors are major targets for SUMO conjugation with mainly negative consequences for gene expression (Girdwood et al., 2004), these results for hibernators suggest that SUMOylation may be a very important mechanism for the suppression of gene transcription during hibernation. Furthermore, the reversible nature of SUMOylation means that a reversal of the process during arousal would allow for the immediate reactivation of the transcription factors needed during euthermia without a need for ATP-expensive resynthesis of these proteins.

Furthermore, a functional link between SUMOylation and the formation of nuclear bodies has been found. Nuclear bodies are formed from aggregates of proteins, most of them SUMOylated, and include transcription factors, chromatin modifiers, and proteins involved in genomic maintenance (Sternsdorf et al., 1997). Formation or disruption of nuclear bodies is associated with changes in cell proliferation, differentiation, and survival status (Zhong et al., 2000). In particular, the formation of heterogeneous ectopic ribonucleoprotein-derived structures (HERDS) has been linked with a number of states that are known to include transcriptional arrest (Biggiogera and Pellicciari, 2000). Nuclear body formation may regulate transcription in at least three ways: (1) by titrating the effective concentrations of nuclear transcription factors by sequestration/release, (2) by mediating post-translational modifications to transcription factors that may occur preferentially in the nuclear body, or (3) by acting as subnuclear compartmentalization centres (Zhong et al., 2000). The formation of several types of torpor phase-specific nuclear bodies has been extensively examined in hibernating dormice, Glis glis (summarized in Malatesta et al., 2001). These disappear rapidly upon arousal and, therefore, appear to be storage/assembly sites for molecules needed for the rapid and massive resumption of transcriptional and post-transcriptional activities upon arousal (Malatesta et al., 2001). Storage of SUMOylated proteins may be one role of nuclear body formation during torpor (Lee et al., 2007). Hence, the formation of nuclear bodies may be another effective method of global transcriptional suppression during hibernation. Interestingly, the delta opioid D-Ala2- D-Leu5 enkephalin, which mimics the activity of the hibernation induction trigger (Oeltgen et al., 1988), delayed the disassembly of nuclear bodies during in vitro studies with G. glis liver (Malatesta et al., 2001). This provides more evidence that nuclear body formation and protein SUMOylation has a physiological function in hibernation. The delta opioid also induces a reversible hibernation-like state in HeLa cells that is characterized by the accumulation of ribonucleoprotein bodies (Vecchio et al., 2006).

\section{miRNA control of hibernation: the next venture?}

Mechanisms that directly regulate transcription (as discussed above) are a main control on gene expression just as control over the ribosomal machinery (including regulation of initiation and elongation factors and polysome assembly/disassembly) are 
major controls over protein synthesis. However, in between transcription and translation there are other opportunities for regulatory input, specifically controls that affect mRNA including its processing, its longevity, and its availability to the translational machinery. Global mechanisms for regulating mRNA may also be part of the overall suppression of metabolism during hibernation. Total mRNA transcript levels do not appear to change significantly over cycles of hibernation/arousal so there must be mechanisms that stabilize and preserve transcripts throughout a torpor bout so that they are available again for immediate translation when the animal arouses. One of these is the physical association of mRNA transcripts with monosomes or with ribonucleoprotein particles. One aspect of translational suppression during hibernation is polysome dissociation so that most ribosomes are sequestered into the translationally-silent monosome fraction during hibernation, taking with them a high proportion of cellular mRNA transcripts (Frerichs et al., 1998; Knight et al., 2000; Hittel and Storey, 2002). Only transcripts that are preferentially translated during hibernation, such as fabp (fatty acid binding protein) remained associated with polysomes (Hittel and Storey, 2002).

Another potential mechanism for controlling the expression of mRNA transcripts is via the action of microRNAs (miRNAs). These recently discovered entities are one of the current "hot topics" in cellular regulation. miRNAs are small non-coding transcripts (19-25 nucleotides in length) that are known to regulate gene expression by binding to target mRNAs and either targeting them for degradation or preventing their translation (Bartel, 2004). They have been implicated in translational control in both healthy and disease models of development, insulin secretion, apoptosis, and cancer, among others and, therefore, have potentially wide and important roles to play in cellular metabolism (O'Driscoll, 2006). It is now presumed that these evolutionary conserved molecules represent as much as $3 \%$ of the human genome (O'Driscoll, 2006) and that they regulate $30-50 \%$ of all proteincoding genes (Huppi et al., 2007).

The miRNA processing pathway starts with the conversion of primary miRNA to pre-miRNA by the nuclear enzyme Drosha. Pre-miRNAs are then exported from the nucleus to the cytoplasm via the transporter exportin-5 (Yi et al., 2003) where they are cleaved into 19-25 nucleotide long pieces by the DICER enzyme (Lee et al., 2002). These smaller miRNAs can then bind to an RNA-induced silencing complex that guides them toward their target mRNAs (Hutvagner and Zamore, 2002). Unlike small interfering RNAs, it has been shown that the mode of action of miRNAs relies more on inhibiting translation of a given mRNA than cleaving it (Zeng et al., 2003). As a general rule, a perfect match between the processed miRNA and its target transcript leads to mRNA cleavage whereas an imperfect match leads to translational inhibition. Translationally-repressed mRNAs have two general fates; storage into cytoplasmic foci also known as Pbodies or degradation via the mRNA-decay pathway (Pillai et al., 2007). The number of $\mathrm{P}$-bodies increases upon exposure to stresses such as glucose deprivation, osmotic stress, and exposure to UV light. Hence, conditions including hypothermia, ischemia and hypoxia during torpor would be likely to produce an increase in $\mathrm{P}$-bodies. One interesting point to consider that is relevant to hibernation is that $m R N A$ storage is a dynamic process meaning that, depending on the external conditions, stored $\mathrm{mR}$ NAs can re-enter both the decay pathway or, more importantly, the translational pathway. Thus, miRNA-mediated reversible mRNA transcript sequestering into P-bodies would provide an explanation for the modality by which hibernators are able to rapidly emerge from periods of deep torpor and reestablish normal euthermic metabolism within minutes to hours. This way, hibernators would have a "jump-start" on the production of new proteins during arousal without the energy expense or time delay involved in reactivating gene transcription. This could be particularly important for an immediate production of proteins that are critical during arousal itself or in the immediate repair or reactivation of key cellular processes. Thus, we propose that miRNAs could have an important regulatory role in hibernation since they provide a mechanism for the inhibition and storage of valuable mRNA transcripts during prolonged torpor bouts. We hypothesize that this type of control would be of primary importance for animals entering and exiting torpor as it would allow storage and release of mRNAs (Figure 3).

We have begun to investigate the possible role of microRNA in the regulation of hibernation. In initial studies we used RT-PCR to quantify the expression of selected miRNAs in four organs of euthermic versus hibernating thirteen-lined ground squirrels (Morin et al., 2008b). Data for kidney are shown in Figure 4. Of the five miRNAs assessed in this organ, mir-1 and mir-21 were both significantly increased in kidney of hibernating versus euthermic animals by 2.0- and 1.3-fold, respectively. Previous studies have indicated that mir-1 is mainly expressed in heart and skeletal muscle of mammals (Lagos-Quintana et al., 2002) but low levels were found in various other mouse tissues (Thomson et al., 2004). Mir-1 can down-regulate the expression of a wide variety of mRNAs (Lim et al., 2005) and mir-1 (as well as mir-206) have mRNA targets that are involved in muscle cell proliferation and gene expression such as HDAC4, a histone deacetylase that leads to gene repression in muscle (Chen et al., 2006). Mir-21 has been linked to anti-apoptotic properties in glioblastomas and breast cancer (Chan et al., 2005; lorio et al., 2005). Kidney function is largely shut down during torpor and, hence, selective increases in certain types of miRNAs could be key to suppressing the expression of specific target groups of mRNAs that are under the control of mir-1 or mir-21. Furthermore, we are beginning to

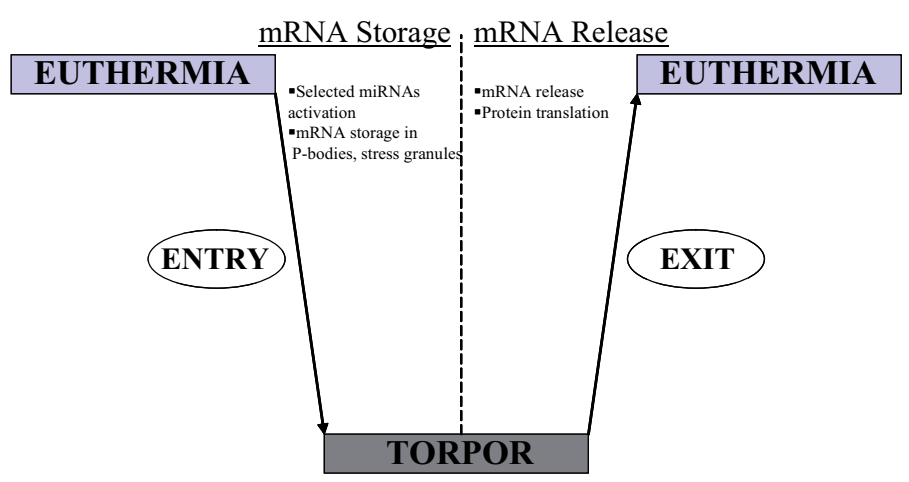

Fig. 3. A proposed model for the role of $\mathbf{P}$-bodies in rapid entry/exit from torpor. Activation of miRNA repression results in mRNAs being sequestered in cytoplasmic P-bodies. Derepression of mRNAs permits renewed protein synthesis thereby facilitating the return to euthermic function during interbout arousals. 


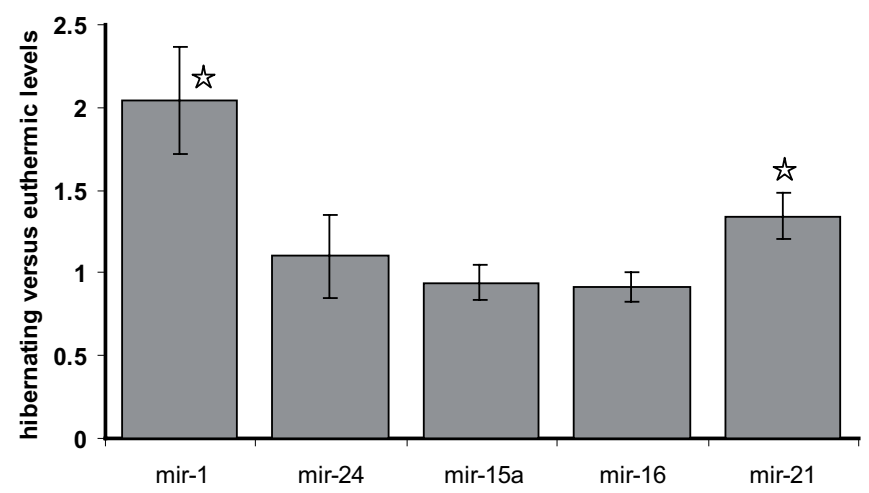

Fig. 4. Effects of hibernation on the relative levels of five miRNA species in ground squirrel (S. tridecemlineatus) kidney. RT-PCR was used to amplify each miRNA as well as 5S rRNA which was used to normalize expression levels. The histogram shows the ratio of normalized PCR product levels in kidney of hibernating versus euthermic ground squirrels. Data are means \pm SEM for $n=5$ trials on different animals. Significance testing used the Student $t$-test to compare hibernating and euthermic values (* - significantly different, $P<0.05$ ); data were then plotted as ratios, hibernating:euthermic. Data are from Morin et al. (2008).

find that inhibition of apoptosis is a critical component of cytoprotection and long term viability in multiple animal systems of hypometabolism. Enhanced levels of mir-21 in kidney may contribute to this action during long term torpor in hibernators.

Much effort is currently underway to find target(s) of miRNAs in mammals. A long list of miRNAs has been identified, but the target mRNAs that they bind to and repress are less clear. Based on studies performed to date, a number of miRNA types could be important in regulating entry, maintenance and exit of hibernation. The miRNAs involved in cell cycle regulation and progression would be interesting to monitor since tight control and suppression of cell cycle progression, growth and differentiation is necessarily an integral part of the hypometabolic state. The miRNAs that have been identified as either oncogenic or tumor suppressive should also be investigated; for example, mir-15a and mir-16 were identified as tumor suppressors due to their marked downregulation in chronic lymphocytic leukemia (Calin et al., 2002). Although levels of these two did not change in kidney during hibernation (Figure 4), they may be important in other organs. Other miRNAs that have been linked to lipid metabolism, such as mir-122a (Esau et al., 2006) could also be investigated in hibernating mammals because of the clear shift to a fatty acid based catabolism during torpor. The miRNAs cited above represent only a small fraction of the total number of identified mammalian miRNAs. Further exploration of the expression patterns of these and other miRNAs in organs of hibernating animals, coupled with continuing progress in linking miRNAs with their mRNA targets, should open the door to uncovering both specific and global controls by miRNAs in hibernation and other states of hypometabolism.

\section{Outlook}

This review has highlighted multiple mechanisms of transcriptional and translational control that underlie the phenomenon of mammalian hibernation, a state of cold torpor where metabolic rate is strongly suppressed and where reversible biochemical controls are applied to regulate coordinated transitions to a hypometabolic state and provide long term cytoprotection. We have summarized recent advances on multiple fronts including transcription control by transcription factors, SUMOylation, and epigenetic mechanisms such as histone modification as well as the potential involvement of microRNA in suppressing the expression of mRNA transcripts during torpor. This latter mechanism, only recently discovered, seems to be well-suited for controlling the cycles of gene silencing versus gene activation that hibernators would experience over serial torpor/arousal cycles throughout the winter. Much remains to be determined about the regulation of gene expression in hibernating mammals and the answers obtained from this continuing research will not only help us to understand the underlying principles of hypometabolism across phylogeny but will highlight potential strategies that can be used to make inducible hypometabolism a valid intervention strategy in human biology and medicine.

\section{Acknowledgements}

Research done in the Storey lab was funded by the NSERC Canada. We thank Dr. J.M. Hallenbeck, National Institute of Neurological Disorders and Stroke (NIH, Bethesda, MD) for providing us with ground squirrel tissue samples and J.M. Storey for editorial review of the manuscript.

\section{References}

ANDREWS, M.T., SQUIRE, T.L., BOWEN, C.M. and ROLLINS, M.B. (1998). Lowtemperature carbon utilization is regulated by novel gene activity in the heart of a hibernating mammal. Proc. Natl. Acad. Sci. USA 95: 8392-8397.

BARTEL, D.P. (2004). MicroRNAs: genomics, biogenesis, mechanism and function. Cell 116: 281-297.

BERGER, J. and MOLLER, D.E. (2002). The mechanisms of action of PPARs. Ann. Rev. Med. 53: 409-435.

BERRIEL DIAZ, M., LANGE, M., HELDMAIER, G. and KLINGENSPOR, M. (2004). Depression of transcription and translation during daily torpor in the Djungarian hamster (Phodopus sungorus). J. Comp. Physiol. B 174: 495-502.

BIGGIOGERA, M. and PELLICCIARI, C. (2000). Heterogeneous ectopic RNPderived structures (HERDS) are markers of transcriptional arrest. FASEB J. 14: 828-834.

BOCHAROVA, L.S., GORDON, R. and ARKHIPOV, V.I. (1992). Uridine uptake and RNA synthesis in the brain of torpid and awakened ground squirrels. Comp. Biochem. Physiol. B 101: 189-192.

BROOKS, S.P.J. and STOREY, K.B. (1992). Mechanisms of glycolytic control during hibernation in the ground squirrel Spermophilus lateralis. J. Comp. Physiol. B 162: 23-28.

BRUNET, A., SWEENEY, L.B., STURGILL, J.F., CHUA, K.F., GREER, P.L., LIN, Y., TRAN, H., ROSS, S.E., MOSTOSLAVSKY, R., COHEN, H.Y., HU, L.S., CHENG, H.L., JEDRYCHOWSKI, M.P., GYGI, S.P., SINCLAIR, D.A., ALT, F.W. and GREENBERG, M.E. (2004). Stress-dependent regulation of FOXO transcription factors by the SIRT1 deacetylase. Science 303: 2011-2015.

BUCK, M.J. and BARNES B.M. (2000). Effects of ambient temperature on metabolic rate, respiratory quotient, and torpor in an arctic hibernator. Am. J. Physiol. 279: R255-R262.

CALIN, G.A., SEVIGNANI, C., DUMITRU, C.D., HYSLOP, T., NOCH, E., YENDAMURI, S., SHIMIZU, M., RATTAN, S., BULLRICH, F., NEGRINI, M. and CROCE, C.M. (2004). Human microRNA genes are frequently located at fragile sites and genomic regions involved in cancers. Proc. Natl. Acad. Sci. USA 101: 2999-3004.

CAREY, H.V., ANDREWS, M.T. and MARTIN, S.L. (2003). Mammalian hibernation: cellular and molecular responses to depressed metabolism and low temperature. Physiol. Rev. 83: 1153-1181. 
CHAN, J.A., KRICHEVSKY, A.M. and KOSIK, K.S. (2005). MicroRNA-21 is an antiapoptotic factor in human glioblastoma cells. Cancer Res. 65: 6029-6033.

CHEN, J.F., MANDEL, E.M., THOMSON, J.M., WU, Q., CALLIS, T.E., HAMMOND, S.M., CONLON, F.L. and WANG, D.Z. (2006). The role of microRNA-1 and microRNA-133 in skeletal muscle proliferation and differentiation. Nat. Genet. 38: 228-233.

CHEN, Y., MATSUHITA, M., NAIRN, A.C., DAMUNI, Z., Cai, D., FRERICHS, K.U. and HALLENBECK, J.M. (2001). Mechanisms for increased levels of phosphorylation of elongation factor-2 during hibernation in ground squirrels. Biochemistry 40: 11565-11570.

CHENG, A.M., BYROM, M.W., SHELTON, J. and FORD, L.P. (2005). Antisense inhibition of human miRNAs and indications for an involvement of miRNA in cell growth and apoptosis. Nucl. Acids Res. 33: 1290-1297.

CHEUNG, P., ALLIS, C.D. and SASSONE-CORSI, P. (2000). Signaling to chromatin through histone modifications. Cell 103: 263-271.

CLARK, S.J., HARRISON, J., PAUL, C.L. and FROMMER, M. (1994). High sensitivity mapping of methylated cytosines. Nucleic Acids Res. 22: 2990-2997.

CRAWFORD, F.I., HODGKINSON, C.L., IVANOVA, E.A., LOGUNOVA, L.B., EVANS, G.J., STEINLECHNER, S. and LOUDON, A.S. (2007). The influence of torpor on cardiac expression of genes involved in the circadian clock and protein turnover in the Siberian hamster (Phodopus sungorus). Physiol. Genomics 31: $521-30$

DAVIE, J.R. (1998). Covalent modifications of histones: expression from chromatin templates. Curr. Opin. Genet. Dev. 8: 173-178.

DENU, J.M. (2003). Linking chromatin function with metabolic networks: Sir2 family of NAD(+)-dependent deacetylases. Trends Biochem. Sci. 28: 41-48.

DOBROVIC, A. and SIMPFENDORFER, D. (1997). Methylation of the BRCA1 gene in sporadic breast cancer. Cancer Res. 57: 3347-3350.

EDDY, S.F. and STOREY, K.B. (2002). Dynamic use of cDNA arrays: heterologous probing for gene discovery and exploration of organismal adaptation to environment stress. In: Cell and Molecular Responses to Stress (Storey, K.B. and Storey, J.M., eds.), Vol. 3: Sensing, Signaling and Cell Adaptation. Elsevier Press, Amsterdam, pp. 315-325.

EDDY, S.F. and STOREY, K.B. (2003). Differential expression of Akt, PPARgamma, and PGC-1 during hibernation in bats. Biochem. Cell Biol. 81: 269-274.

EDDY, S.F. and STOREY, K.B. (2007). p38(MAPK) regulation of transcription factor targets in muscle and heart of the hibernating bat, Myotis lucifugus. Cell Biochem. Funct. 25: 759-765.

EDDY, S.F., MORIN, P. Jr. and STOREY, K.B. (2004). Cloning and expression of PPAR-gamma and PGC-1alpha from the hibernating ground squirrel, Spermophilus tridecemlineatus. Mol. Cell. Biochem. 269: 175-182.

EDDY, S.F., MCNALLY, J.D. and STOREY, K.B. (2005). Up-regulation of a thioredoxin peroxidase-like protein, proliferation associated gene, in hibernating bats. Arch. Biochem. Biophys. 435: 101-111.

EDEN, S., HASHIMSHONY, T., KESHET, I., CEDAR, H. and THORNE, A.W. (1998). DNA methylation models histone acetylation. Nature 394: 842.

ESAU, C., DAVIS, S., MURRAY, S.F., YU, X.X., PANDEY, S.K., PEAR, M., WATTS, L., BOOTEN, S.L., GRAHAM, M., MCKAY, R., SUBRAMANIAM, A., PROPP, S., LOLLO, B.A., FREIER, S., BENNETT, C.F., BHANOT, S. and MONIA, B.P. (2006). miR-122 regulation of lipid metabolism revealed by in vivo antisense targeting. Cell Metab. 3: 87-98.

FRAGA, M.F. and ESTELLER, M. (2007). Epigenetics and aging: the targets and the marks. Trends Genet. 23: 413-418.

FRANK, C.L. and STOREY, K.B. (1995). Optimal depot fat composition for hibernation by golden-mantled ground squirrels (Spermophilus lateralis). J. Comp. Physiol. B 164: 536-542.

FRERICHS, K.U., SMITH, C.B., BRENNER, M., DEGRACIA, D.J., KRAUSE, G.S., MARRONE, L., DEVER, T.E. and HALLENBECK, J.M. (1998). Suppression of protein synthesis in brain during hibernation involves inhibition of protein initiation and elongation. Proc. Natl. Acad. Sci. USA 95: 14511-14516.

FRESCAS, D., VALENTI, L. and ACCILI, D. (2005). Nuclear trapping of the forkhead transcription factor FoxO1 via Sirt-dependent deacetylation promotes expression of glucogenetic genes. J. Biol. Chem. 280: 20589-20595.

FRYE, R.A. (2000). Phylogenetic classification of prokaryotic and eukaryotic Sir2like proteins. Biochem. Biophys. Res. Commun. 273: 793-798.
FUJII, G., NAKAMURA, Y., TSUKAMOTO, D., ITO, M., SHIBA, T. and TAKAMATSU, N. (2006). CpG methylation at the USF-binding site is important for the liverspecific transcription of the chipmunk HP-27 gene. Biochem J. 395: 203-209.

GEISER, F. (2004). Metabolic rate and body temperature reduction during hibernation and daily torpor. Annu. Rev. Physiol. 66: 239-274.

GIRDWOOD, D.W., TATHAM, M.H. and HAY, R.T. (2004). SUMO and transcriptional regulation. Semin. Cell. Dev. Biol. 15: 201-210.

HARDEN, S.V., TOKUMARU, Y., WESTRA, W.H., GOODMAN, S., AHRENDT, S.A., YANG, S.C. and SIDRANSKY, D. (2003). Gene promoter hypermethylation in tumors and lymph nodes of stage I lung cancer patients. Clin. Cancer Res. 9: 1370-1375.

HAY, R.T. (2005). SUMO: a history of modification. Mol. Cell. 18: 1-12.

HELLER, H.C. and RUBY, N.F. (2004). Sleep and circadian rhythms in mammalian torpor. Annu. Rev. Physiol. 66: 275-289.

HITTEL, D., and STOREY, K.B. (2002). The translation state of differentially expressed mRNAs in the hibernating thirteen-lined ground squirrel (Spermophilus tridecemlineatus). Arch. Biochem. Biophys. 401: 244-254.

HOPFL, G., OGUNSHOLA, O. and GASSMANN, M. (2003). Hypoxia and high altitude. The molecular response. Adv. Exp. Med. Biol. 543: 89-115.

HUPPI, K., VOLFOVSKY, N., MACKIEWICZ, M., RUNFOLA, T., JONES, T.L., MARTIN, S.E., STEPHENS, R. and CAPLEN, N.J. (2007). MicroRNAs and genomic instability. Sem. Cancer Biol. 17: 65-73.

HUTVAGNER,G. and ZAMORE, P.D. (2002). A miRNA in a multiple-turnover RNAi enzyme complex. Science 297: 2056-2060.

IORIO, M.V., FERRACIN, M., LIU, C.G., VERONESE, A., SPIZZO, R., SABBIONI, S., MAGRI, E., PEDRIALI, M., FABBRI, M., CAMPIGLIO, M., MENARD, S., PALAZZO, J.P., ROSENBERG, A., MUSIANI, P., VOLINIA, S., NENCI, I., CALIN, G.A., QUERZOLI, P., NEGRINI, M. and CROCE, C.M. (2005). MicroRNA gene expression deregulation in human breast cancer. Cancer Res. 65: 70657070.

JENUWEIN, T. and ALLIS, C.D. (2001). Translating the histone code. Science 293: 1074-1080.

KIM, E., DU, L., BREGMAN, D.B. and WARREN S.L. (1997). Splicing factors associate with hyperphosphorylated RNA polymerase II in the absence of premRNA. J. Cell. Biol. 136: 19-28.

KNIGHT, J.E., NARUS, E.N., MARTIN, S.L., JACOBSON, A., BARNES, B.M. and BOYER, B.B. (2000). mRNA stability and polysome loss in hibernating Arctic ground squirrels (Spermophilus parryii). Mol. Cell. Biol. 20: 6374-6379.

LAGOS-QUINTANA, M., RAUHUT, R., YALCIN, A., MEYER, J., LENDECKEL, W. and TUSCHL, T. (2002). Identification of tissue-specific microRNAs from mouse. Curr. Biol. 12: 735-739.

LAGOUGE, M., ARGMANN, C., GERHART-HINES, Z., MEZIANE, H., LERIN, C., DAUSSIN, F., MESSADEQ, N., MILNE, J., LAMBERT, P., ELLIOTT, P., GENY, B., LAAKSO, M., PUIGSERVER, P. and AUWERX, J. (2006). Resveratrol improves mitochondrial function and protects against metabolic disease by activating SIRT1 and PGC-1alpha. Cell 127: 1109-1122.

LANDE-DINER, L. and CEDAR, H. (2005). Silence of the genes - mechanisms of long-term repression. Nat. Rev. Genet. 6: 648-654.

LEE, Y., JEON, K.,nLEE, J.T., KIM, S., and KIM, V.N. (2002). MiRNA maturation: stepwise processing and subcellular localization. EMBO J. 21: 4663-4670.

LEE, Y.J. and HALLENBECK, J.M. (2006). Insights into cytoprotection from ground squirrel hibernation, a natural model of tolerance to profound brain oligaemia. Biochem. Soc. Trans. 34: 1295-1298.

LEE, Y.J., MIYAKE, S., WAKITA, H., MCMULLEN, D.C., AZUMA, Y., AUH, S. and HALLENBECK, J.M. (2007). Protein SUMOylation is massively increased in hibernation torpor and is critical for the cytoprotection provided by ischemic preconditioning and hypothermia in SHSY5Y cells. J. Cereb Blood Flow Metab. 27: 950-962.

LIM, L.P., LAU, N.C., GARRETT-ENGELE, P., GRIMSON, A., SCHELTER, J.M., CASTLE, J., BARTEL, D.P., LINSLEY, P.S. and JOHNSON, J.M. (2005). Microarray analysis shows that some microRNAs downregulate large numbers of target mRNAs. Nature 433: 769-773.

MACDONALD, J.A. and STOREY, K.B. (1999). Regulation of ground squirrel $\mathrm{Na}^{+}$ $\mathrm{K}^{+}$-ATPase activity by reversible phosphorylation during hibernation. Biochem. Biophys. Res. Commun. 254: 424-429. 
MACK, G.S. (2006). Epigenetic cancer therapy makes headway. J. Natl. Cancer Inst. 98: 1443-1444.

MALATESTA, M., LUCHETTI, F., MARCHEGGIANI, F., FAKAN, S. and GAZZANELLI, G. (2001). Disassembly of nuclear bodies during arousal from hibernation: an in vitro study. Chromosoma 110: 471-477.

MALYSHEVA, I.N., STOREY, K.B., LOPINA, O.D. and RUBTSOV, A.M. (2001) Ca-ATPase activity and protein composition of sarcoplasmic reticulum membranes isolated from skeletal muscles of typical hibernator, the ground squirre Spermophilus undulatus. Biosci. Rep. 21: 831-838.

MAMADY, H. and STOREY, K.B. (2006). Up-regulation of the endoplasmic reticulum molecular chaperone GRP78 during hibernation in thirteen-lined ground squirrels. Mol. Cell. Biochem. 292: 89-98.

MAMADY, H. and STOREY, K.B. (2008). Coping with stress: expression of ATF4 ATF6 and downstream targets in organs of hibernating ground squirrels. Arch. Biochem. Biophys. 477: 77-85.

MIAO, F., WU, X., ZHANG, L., YUAN, Y.C., RIGGS, A.D. and NATARAJAN, R. (2007). Genome-wide analysis of histone lysine methylation variations caused by diabetic conditions in human monocytes. J. Biol. Chem. 282: 13854-13863.

MORIN, P. Jr. and STOREY, K.B. (2005). Cloning and expression of hypoxiainducible factor 1alpha from the hibernating ground squirrel, Spermophilus tridecemlineatus. Biochem. Biophys. Acta 1729: 32-40.

MORIN, P. Jr. and STOREY, K.B. (2006). Evidence for a reduced transcriptional state during hibernation in ground squirrels. Cryobiology 53: 310-318.

MORIN, P. Jr., NI, J., MCMULLEN, D.C. and STOREY, K.B. (2008a). Expression of Nrf2 and its downstream gene targets in hibernating thirteen-lined ground squirrels, Spermophilus tridecemlineatus. Mol. Cell. Biochem. 312: 121-129.

MORIN, P. Jr., DUBUC, A. and STOREY, K.B. (2008b). Differential expression of microRNA species in organs of hibernating ground squirrels: a role in translational suppression during torpor. Biochim. Biophys. Acta 1779: 628-633.

MOTTA, M.C., DIVECHA, N., LEMIEUX, M., KAMEL, C., CHEN, D., GU, W., BULTSMA, Y., MCBURNEY, M. and GUARENTE, L. (2004). Mammalian SIRT1 represses forkhead transcription factors. Cell 116: 551-563.

O'DRISCOLL, L. (2006). The emerging world of microRNA. Anticancer Res. 26(6B): 4271-7278.

OELTGEN, P.R., NILEKANI, S.P., NUCHOLS, P.A., SPURRIER, W.A. and SU, T.P. (1988). Further studies on opioids and hibernation: delta opioid receptor ligand selectively induced hibernation in summer-active ground squirrels. Life Sci. 43: 1565-1574.

OHTANI-FUJITA, N., DRYJA, T.P., RAPAPORT, J.M., FUJITA, T., MATSUMURA, S., OZASA, K., WATANABE, Y., HAYASHI, K., MAEDA, K., KINOSHITA, S., MATSUMURA, T., OHNISHI, Y., HOTTA, Y., TAKAHASHI, R., KATO, M.V., ISHIZAKI, K., SASAKI, M.S., HORSTHEMKE, B., MINODA, K. and SAKAI, T. (1997). Hypermethylation in the retinoblastoma gene is associated with unilateral, sporadic retinoblastoma. Cancer Genet. Cytogenet. 98: 43-49.

OSBORNE, P.G., GAO, B., and HASHIMOTO, M. (2004). Determination in vivo of newly synthesized gene expression in hamsters during phases of the hibernation cycle. Japan J. Physiol. 54: 295-305.

PICARD, F., KURTEV, M., CHUNG, N., TOPARK-NGARM, A., SENAWONG, T., MACHADO De OLIVEIRA, R., LEID, M., MCBURNEY, M.W. and GUARENTE, L. (2004). Sirt1 promotes fat mobilization in white adipocytes by repressing PPAR-gamma. Nature 429: 771-776.

PILLAI, R.S., BHATTACHARYYA, S.N. and FILIPOWICZ, W. (2007). Repression of protein synthesis by miRNAs: how many mechanisms. Trends Cell Biol. 17: 118-126.

PRENDERGAST, B.J., FREEMAN, D.A., ZUCKER, I. and NELSON, R.J. (2002). Periodic arousal from hibernation is necessary for initiation of immune responses in ground squirrels. Am. J. Physiol. 282: R1054-R1062.

RATCLIFFE, P.J., O'ROURKE, J.F., MAXWELL, P.H. and PUGH, C.W. (1998). Oxygen sensing, hypoxia-inducible factor-1 and the regulation of mammalian gene expression. J. Exp. Biol. 201: 1153-1162.

RODGERS, J.T., LERIN, C., HAAS, W., GYGI, S.P., SPIEGELMAN, B.M. and PUIGSERVER, P. (2005). Nutrient control of glucose homeostasis through a complex of PGC-1alpha and SIRT1. Nature 434: 113-118.
SARRAF, S.A. and STANCHEVA, I. (2004). Methyl-CpG binding protein MBD1 couples histone $\mathrm{H} 3$ methylation at lysine 9 by SETDB1 to DNA replication and chromatin assembly. Mol. Cell 15: 595-605.

SEMENZA, G.L. (2000). HIF-1: mediator of physiological and pathophysiological responses to hypoxia. J. Appl. Physiol. 88: 1474-1480.

SHAVLAKADZE, T. and GROUNDS, M. (2006). Of bears, frogs, meat, mice and men: complexity of factors affecting skeletal muscle mass and fat. Bioessays 28: 994-1009.

SHI, T., WANG, F., STIEREN, E. and TONG, Q. (2005). SIRT3, a mitochondrial sirtuin deacetylase, regulates mitochondrial function and thermogenesis in brown adipocytes. J. Biol. Chem. 280: 13560-13567.

STERNSDORF, T., JENSEN, K. and WILL, H. (1997). Evidence for covalent modification of the nuclear dot-associated proteins PML and Sp100 by PIC1/ SUMO-1. J. Cell. Biol. 139: 1621-134.

STOREY, K.B. (2003). Mammalian hibernation: transcriptional and translational controls. Adv. Exp. Med. Biol. 543: 21-38.

STOREY, K.B. (2004). Cold, ischemic organ preservation: lessons from natural systems. J. Invest. Med. 52: 315-322.

STOREY, K.B. and STOREY, J.M. (1990). Facultative metabolic rate depression: molecular regulation and biochemical adaptation in anaerobiosis, hibernation, and estivation. Quart. Rev. Biol. 65, 145-174.

STOREY, K.B. and STOREY, J.M. (2004). Metabolic rate depression in animals: transcriptional and translational controls. Biol. Rev. Camb. Phil. Soc. 79: 207233.

STOREY, K.B. and STOREY, J.M. (2007). Putting life on 'pause' - molecular regulation of hypometabolism. J. Exp. Biol. 210: 1700-1714.

TATE, P.H. and BIRD A.P. (1993). Effects of DNA methylation on DNA-binding proteins and gene expression. Curr. Opin. Genet. Develop. 3: 226-231.

THOMSON, J.M., PARKER, J., PEROU, C.M. and HAMMOND, S.M.(2004). A custom microarray platform for analysis of microRNA gene expression. Nat. Methods 1: 47-53.

VAN BREUKELEN, F. and MARTIN, S.L. (2002). Reversible depression of transcription during hibernation. J. Comp. Physiol. B 172: 355-361.

VAQUERO, A., SCHER, M., LEE, D., ERDJUMENT-BROMAGE, H., TEMPST, P and REINBERG, D. (2004). Human SirT1 interacts with histone H1 and promotes formation of facultative heterochromatin. Mol. Cell 16: 93-105.

VECCHIO, L., SOLDANI, C., BOTTONE, M.G., MALATESTA, M., MARTIN, T.E., ROTHBLUM, L.I., PELLICCIARI, C. and BIGGIOGERA, M. (2006). DADLE induces a reversible hibernation-like state in HeLa cells. Histochem. Cell Biol. 125: 193-201.

WANG, L.C.H. and LEE, T.F (1996). Torpor and hibernation in mammals: metabolic, physiological and biochemical adaptations. In Handbook of Physiology: Environmental Physiology (Fregley, M.J., and Blatteis, C.M., eds.). Oxford University Press, New York, pp. 507-532.

WAY, J.M., HARRINGTON, W.W., BROWN, K.K., GOTTSCHALK, W.K., SUNDSETH, S.S., MANSFIELD, T.A., RAMACHANDRAN, R.K., WILLSON, T.M. and KLIEWER, S.A. (2001). Comprehensive messenger ribonucleic acid profiling reveals that peroxisome proliferator-activated receptor gamma activation has coordinate effects on gene expression in multiple insulin-sensitive tissues. Endocrinology 142: 1269-1277.

YEUNG, F., HOBERG, J.E., RAMSEY, C.S., KELLER, M.D., JONES, D.R., FRYE, R.A. and MAYO, M.W. (2004). Modulation of NF-kappaB-dependent transcription and cell survival by the SIRT1 deacetylase. EMBO J. 23: 2369-2380.

YI, R., QIN, Y., MACARA, I.G. and CULLEN, B.R. (2003). Exportin-5 mediates the nuclear export of pre-microRNAs and short hairpin RNAs. Genes Dev. 17: 30113016.

ZENG, Y., YI, R. and CULLEN B.R. (2003). MicroRNAs and small interfering RNAs can inhibit mRNA expression by similar mechanisms. Proc. Natl. Acad. Sci. USA 100: $9779-9784$

ZHONG, S. SALOMONI, P. and PANDOLFI, P.P. (2000). The transcriptional role of PML and the nuclear body. Nat. Cell Biol. 2: E85-E90. 


\section{Further Related Reading, published previously in the Int. J. Dev. Biol.}

See our recent Special Issue Fertilization, in honor of David L. Garbers and edited by Paul M. Wassarman and Victor D. Vacquier at: http://www.ijdb.ehu.es/web/contents.php?vol=52\&issue=5-6

\section{Understanding the regulatory genome}

M. Eva Alonso, Bárbara Pernaute, Miguel Crespo, José Luis Gómez-Skarmeta and Miguel Manzanares Int. J. Dev. Biol. (2009) 53: doi: 10.1387/ijdb.072428ma

Transcriptional regulation and the evolution of development. Gregory A Wray Int. J. Dev. Biol. (2003) 47: 675-684

Evolution of cis-regulatory regions versus codifying regions. Francisco Rodríguez-Trelles, Rosa Tarrío and Francisco J Ayala Int. J. Dev. Biol. (2003) 47: 665-673

Epigenetic reprogramming of the genome--from the germ line to the embryo and back again.

K L Arney, S Erhardt, R A Drewell and M A Surani

Int. J. Dev. Biol. (2001) 45: 533-540

From the Aristotelian soul to genetic and epigenetic information: the evolution of the modern concepts in developmental biology at the turn of the century. W A Müller

Int. J. Dev. Biol. (1996) 40: 21-26

2006 ISI **Impact Factor $=3.577^{* *}$

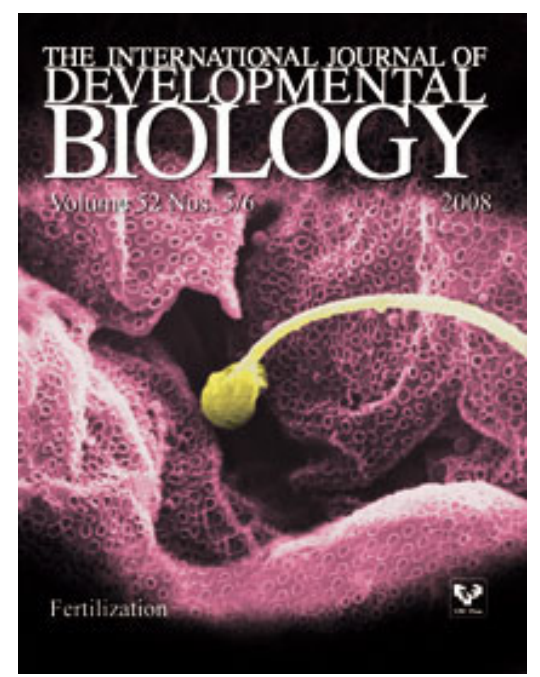

